American Journal of Applied Sciences 9 (6): 851-857, 2012

ISSN 1546-9239

(C) 2012 Science Publications

\title{
Synthesis of Robust Dynamic Controller, Model Predictive Control Based
}

\author{
${ }^{1,2}$ Mohamed Adel Sellami, ${ }^{1}$ Elyes Maherzi and ${ }^{1}$ Mongi Besbes \\ ${ }^{1}$ Department of Electrical Engineering, \\ High School of Technology and Computer Science, Tunisia \\ ${ }^{2}$ Department of Physics and Electronics, Faculty of Sciences, Tunis, Tunisia
}

\begin{abstract}
Problem statement: More advanced control techniques have been developed in recent decades following the great progress of calculations means. Without considering the constraints on system variables, the response of controlled system moves away from the desired response. Hence the control strategy must provide the ability to integrate these constraints in the design phase of the controller. Approach: This study presents a design of robust dynamic controller which was based on the control strategy MPC for an uncertain discrete system described by a multimodel by solving an optimization problem. The Model Predictive Control (MPC) strategy uses a dynamic model of the process in order to predict its future behavior. This control strategy, that we propose, makes it possible to integrate these constraints in the design phase of the controller. The design of the robust dynamic controller must maintain the stability and performance of the system in the presence of uncertainties. The principle of this method was to solve, at each calculation step, a convex optimization problem that calculates the matrices characterizing the dynamic controller. LMI formulation of the constraints, on process variables, was introduced into the design phase of the dynamic controller robust. The optimization study was also implemented in the MATLAB software and simulation studies had been presented. Results: Simulation results had proved the effectiveness of this study. The robust dynamic controller designed for uncertain systems guarantees stability in closed loop systems by integrating constraints on system variables. Conclusion: The described approach explain how to integrate constraints, MPC type, during the phase of design of the robust controller: the simulation concluded on a benchmark proof the powerful of this approach.
\end{abstract}

Key words: Model Predictive Control (MPC), robust dynamic controller, Linear Matrix Inequalities (LMI), discrete multimodels

\section{INTRODUCTION}

In recent years, control engineers have been attracted by the multi-model approach that have used in various industrial applications such as the identification of nonlinear dynamic systems, stability and control of systems (Chadli, 2002; Chadli et al., 2009; Akhenak et al., 2004) and its contribution to the state estimation and diagnosis of systems represented by multimodels (Maherzi et al., 2007; Santhakumar and Asokan, 2010; Kanthalakshmi and Manikandan, 2011).

This approach allows the representation of the dynamic behavior of a nonlinear system as an aggregation of local linear models, (Elfelly et al., 2010). Each one is a linear system valid around an operating point.

This technique reduces the problem of identification of a nonlinear system to an identification of sub-models using input and output data of different operating points.

In this study, we propose the conception of a robust dynamic controller applied to a nonlinear system represented by multimodel approach (Torre and Migliore, 2011; Richalet et al., 2005).

The designing of the dynamic controller is based on the predictive control strategy which consists to resolve, at each calculation step, a convex optimization problem in order to calculate the matrices characterizing the dynamic controller.

Determination of matrices is given by the Linear Matrix Inequalities (LMI) (Boyd et al., 1994) via the LMI toolbox of the Matlab (C) Software.

This study describe how to synthesis a robust dynamic controllers for the control and command uncertain nonlinear systems where uncertainties is polytopic and using an observer.

\section{MATERIALS AND METHODS}

Problem formulation: Let consider the nonlinear system described by the following discrete multi-model Eq. 1:

Corresponding Author: $\quad$ Mohamed Adel Sellami, Department of Electrical Engineering, High School of Technology and Computer Science, Tunisia 
Am. J. Applied Sci., 9 (6): 851-857, 2012

$$
\left\{\begin{array}{l}
x(k+1)=A x(k)+B u(k) \\
y(k)=C x(k)
\end{array}\right.
$$

where, the uncertainties on $\mathrm{A}$ are a convex polytopic type defined by:

With:

$$
\mathrm{A}=\sum_{\mathrm{j}=1}^{\mathrm{N}} \alpha_{\mathrm{j}} \mathrm{A}_{\mathrm{j}}: \alpha \in \Gamma, \Gamma=\left\{\alpha: \alpha_{\mathrm{j}} \geq 0, \sum_{\mathrm{j}=1}^{\mathrm{N}} \alpha_{\mathrm{j}}=1\right\}
$$

Where:

$$
\begin{aligned}
\mathrm{x}(\mathrm{k}) \in \mathbb{R}^{\mathrm{n}}= & \text { The state vector } \\
\mathrm{u}(\mathrm{k}) \in \mathbb{R}^{\mathrm{m}=} & \text { The vector control } \\
\mathrm{y}(\mathrm{k}) \in \mathbb{R}^{\mathrm{q}}= & \text { The output vector } \\
\mathrm{A} \in \mathbb{R}^{\mathrm{n} n}= & \text { The dynamic matrix containing the } \\
& \text { uncertainty } \\
\mathrm{B} \in \mathbb{R}^{\mathrm{n}^{*} \mathrm{~m}=} & \begin{array}{l}
\text { The control matrix and } \mathrm{C} \in \mathbb{R}^{\mathrm{q}^{* \mathrm{n}}} \text { is the } \\
\text { output matrix }
\end{array}
\end{aligned}
$$

This system must satisfy the following condition that the $(\mathrm{A}, \mathrm{B})$ pair of matrices is controllable and the $(\mathrm{A}, \mathrm{C})$ pair of matrices is observable.

So, we propose a control low stabilizing the uncertain system described by (1) at each instant $\mathrm{k}$ by using a dynamic controller based on output feedback in order to minimize a coast function under constraints (Torre and Migliore, 2011). The dynamic controller is given by Eq. 2:

$$
\left\{\begin{array}{l}
\mathrm{x}_{\mathrm{c}}(\mathrm{k}+1)=\mathrm{A}_{\mathrm{c}} \mathrm{x}_{\mathrm{c}}(\mathrm{k})+\mathrm{B}_{\mathrm{c}} \mathrm{y}(\mathrm{k}) \\
\mathrm{u}(\mathrm{k})=\mathrm{C}_{\mathrm{c}} \mathrm{x}_{\mathrm{c}}(\mathrm{k})
\end{array}\right.
$$

Where:

$\mathrm{xc}(\mathrm{k}) \in \mathbb{R}^{\mathrm{n}}$ is The state vector controller, matrices $\mathrm{A}_{\mathrm{c}} \in \mathbb{R}^{\mathrm{n}{ }^{\mathrm{n}}}, \mathrm{B}_{\mathrm{c}} \in \mathbb{R}^{\mathrm{n} * \mathrm{q}}$ and $\mathrm{C}_{\mathrm{c}} \in \mathbb{R}^{\mathrm{m} * \mathrm{n}}$ Define the dynamic controller

Figure 1 describes the synoptic graph of an uncertain system with dynamic controller.

\section{Characterization of unmeasured states:}

Mathematic model of uncertain system based on multi-model approach: Another description of the system described by (1) and (2) is given by Eq. 3:

$$
\left\{\begin{array}{l}
\mathrm{x}_{\mathrm{e}}(\mathrm{k}+1)=\hat{\mathrm{A}}(\mathrm{k}) \mathrm{x}_{\mathrm{e}}(\mathrm{k})+\hat{\mathrm{B}} \mathrm{u}(\mathrm{k}) \\
\mathrm{u}(\mathrm{k})=\hat{\mathrm{K}}(\mathrm{k}) \mathrm{x}_{\mathrm{e}}(\mathrm{k}) \\
\mathrm{y}(\mathrm{k})=\hat{\mathrm{C}} \mathrm{x}_{\mathrm{e}}(\mathrm{k})
\end{array}\right.
$$

Where:

$$
\left\{\begin{array}{l}
\hat{A}(k)=\left[\begin{array}{cc}
A & 0 \\
B_{c}(k) C & A_{c}(k)
\end{array}\right] \in R^{2 n * 2 n} ; \hat{B}(k)=\left[\begin{array}{l}
B \\
0
\end{array}\right] \in R^{2 n * m} \\
\hat{C}(k)=\left[\begin{array}{ll}
C & 0
\end{array}\right] \in R^{q^{*} 2 n} ; \hat{K}(k)=\left[\begin{array}{cc}
0 & \left.C_{c}(k)\right] \in R^{q^{*} 2 n}
\end{array}\right. \\
x_{e}(k)=\left[\begin{array}{c}
x(k) \\
x_{c}(k)
\end{array}\right] \in R^{2 n}
\end{array}\right.
$$

Quadratic function: We consider a coast function of quadratic infinite horizon that weights the value of the control efforts and system states. This function can be expressed as Eq. 4:

$$
\mathrm{J}_{\infty}(\mathrm{k})=\sum_{\mathrm{i}=0}^{\infty}\left[\begin{array}{c}
\mathrm{x}_{\mathrm{e}}(\mathrm{k}+\mathrm{i} \backslash \mathrm{k})^{\mathrm{T}} \cdot \hat{\mathrm{Q}} \cdot \mathrm{x}_{\mathrm{e}}(\mathrm{k}+\mathrm{i} \backslash \mathrm{k}) \\
+\mathrm{u}(\mathrm{k}+\mathrm{i} \backslash \mathrm{k})^{\mathrm{T}} \cdot \mathrm{R} \cdot \mathrm{u}(\mathrm{k}+\mathrm{i} \backslash \mathrm{k})
\end{array}\right]
$$

where, $x_{e}(k+i l k)$ is the expectation value of the state at time $\mathrm{k}+\mathrm{i}$, knowing the state $\mathrm{x}_{\mathrm{e}}(\mathrm{k} \backslash \mathrm{k})$ Let consider the following quadratic function Eq. 5:

$\mathrm{V}_{\mathrm{L}}\left(\mathrm{x}_{\mathrm{e}}(\mathrm{k} \backslash \mathrm{k})\right)=\mathrm{x}_{\mathrm{e}}(\mathrm{k} \backslash \mathrm{k})^{\mathrm{T}} \cdot \mathrm{P} \cdot \mathrm{x}_{\mathrm{e}}(\mathrm{k} \backslash \mathrm{k})$

where, $\mathrm{P}=\mathrm{P}(\mathrm{klk})$ is constant and $\mathrm{V}_{\mathrm{L}}(0)=0$.

This function must satisfy the following inequality Eq. 6:

$$
\begin{aligned}
& \Delta \mathrm{V}_{\mathrm{L}}\left(\mathrm{x}_{\mathrm{e}}(\mathrm{k} \backslash \mathrm{k})\right)=\mathrm{V}_{\mathrm{L}}\left(\mathrm{x}_{\mathrm{e}}(\mathrm{k}+\mathrm{i}+1 \backslash \mathrm{k})\right) \\
& -\mathrm{V}_{\mathrm{L}}\left(\mathrm{x}_{\mathrm{e}}(\mathrm{k}+\backslash \mathrm{k})\right) \\
& \leq-\left[\begin{array}{l}
\mathrm{x}_{\mathrm{e}}(\mathrm{k}+\mathrm{i} \backslash \mathrm{k})^{\mathrm{T}} \cdot \hat{\mathrm{Q}} \cdot \mathrm{x}_{\mathrm{e}}(\mathrm{k}+\mathrm{i} \backslash \mathrm{k}) \\
+\mathrm{u}(\mathrm{k}+\mathrm{i} \backslash \mathrm{k})^{\mathrm{T}} \cdot \mathrm{R} \cdot \mathrm{u}(\mathrm{k}+\mathrm{i} \backslash \mathrm{k})
\end{array}\right]
\end{aligned}
$$

The quadratic function given by (5) represents the upper born of the coast function given by (4); so we can satisfy the following condition Eq. 7:

$\mathrm{J}_{\infty}(\mathrm{k}) \leq \mathrm{V}_{\mathrm{L}}\left(\mathrm{x}_{\mathrm{e}}(\mathrm{k} \backslash \mathrm{k})\right)$

The result given by (7) introduces an approach that consists in synthesizing a dynamic controller based on output feedback by minimizing the quadratic function (5) under the condition (6).

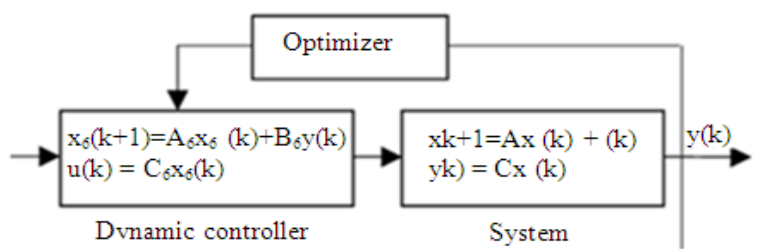

Fig. 1: System controlled by a robust dynamic controller 
Am. J. Applied Sci., 9 (6): 851-857, 2012

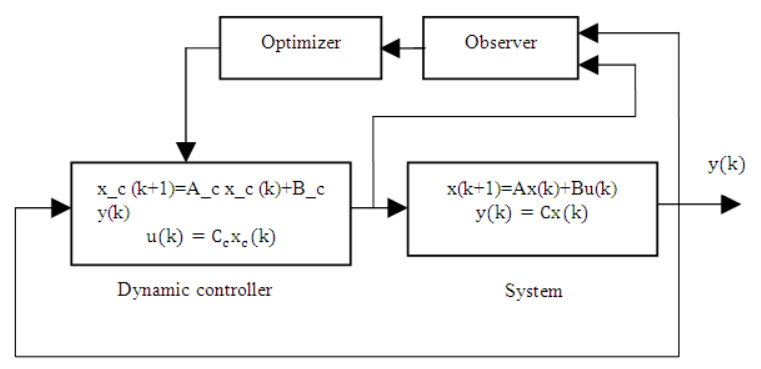

Fig. 2: System controlled by a robust dynamic controller with an observer

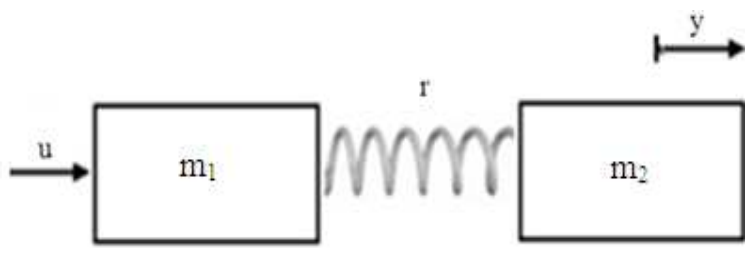

Fig. 3: Synoptic of a real system: two masses connected by a spring

The state vector can be expressed as Eq. 8:

$$
\mathrm{x}(\mathrm{k})=\left[\begin{array}{c}
\mathrm{x}_{\mathrm{r}}(\mathrm{k}) \\
\mathrm{x}_{\mathrm{m}}(\mathrm{k})
\end{array}\right] \in \mathrm{R}^{\mathrm{n}}
$$

Where:

$\mathrm{x}_{\mathrm{r}}(\mathrm{k}) \in \mathrm{R}^{\mathrm{n}-\mathrm{p}}:$ unmeasured states:

$\mathrm{xm}(\mathrm{k}) \in \mathrm{R}^{\mathrm{p}}$ : measured states:

$\mathrm{x}_{\mathrm{r}}(\mathrm{k})$ belongs to the convex polytope defined from membership intervals of xr components Eq. 9:

$\mathrm{x}_{\mathrm{r}, \mathrm{i}}^{\min } \leq \mathrm{x}_{\mathrm{r}, \mathrm{i}}(\mathrm{k}) \leq \mathrm{x}_{\mathrm{r}, \mathrm{i}}^{\max }$

$\mathrm{i}=1,2, \ldots, \mathrm{n}-\mathrm{p}$

$\mathrm{X}_{\mathrm{r}}^{\mathrm{j}}(\mathrm{k}), \mathrm{j}=1,2, \ldots, 1$, the vertices of this polytope. The uncertain states are given by Eq. 10:

$\chi_{j}(k)=\left[\begin{array}{c}x_{r}^{j}(k) \\ x_{m}(k)\end{array}\right] \in R^{n}$

$\mathrm{j}=1,2, \ldots, 1$; follows:

The membership of the vector field is given as

$$
\Omega=\mathrm{C}_{\mathrm{o}}\left\{\chi_{\mathrm{j}}, \mathrm{j}=1,2, \ldots, \mathrm{l}\right\}
$$

$$
\mathrm{x}(\mathrm{k})=\sum_{\mathrm{j}=1}^{1} \lambda_{\mathrm{j}} \chi_{\mathrm{j}}(\mathrm{k}) ; \lambda \in \Gamma ; \Gamma=\left\{\lambda ; \lambda_{\mathrm{j}} \geq 0 ; \sum_{\mathrm{j}=1}^{1} \lambda_{\mathrm{j}}=1\right\}
$$

Design of the robust dynamic controller:

Observer: Let consider that $\chi(\mathrm{k})=\chi(\mathrm{k} \mid \mathrm{k})$ the state value of (1) and $x_{c}(k \mid k)$ the state value of the controller (2) at each instant $\mathrm{k}$. Vectors $\mathrm{u}_{\max }$ and $\mathrm{y}_{\max }$ are knowing.

Uncertain discrete system (1) is asymptotically stabilized by a dynamic controller with output feedback, minimizing an upper born of the quadratic constrained if it exist at each sampling time matrices $\mathrm{Z}, \mathrm{H} \in \mathbb{R}^{\mathrm{n}^{\mathrm{*n}}}, \mathrm{L} \in \mathbb{R}^{\mathrm{m}^{* \mathrm{n}} \mathrm{n}}, \mathrm{F}, \mathrm{H} \in \mathbb{R}^{\mathrm{n} * \mathrm{q}}$ and symmetric positive matrices definite $X, Y, P \in \mathbb{R}^{\mathrm{n}^{* n} \mathrm{n}}$ solutions of the following optimization problem Eq. 11-15 (Torre and Migliore, 2011; Ababneh et al., 2011)

miny

Under:

$\left(\begin{array}{ccc}\mathrm{Y} & \mathrm{I} & {\left[\mathrm{Y}_{\mathrm{j}}(\mathrm{k})+\mathrm{Vx}_{\mathrm{c}}(\mathrm{k})\right]} \\ \mathrm{I} & \mathrm{X} & \chi_{\mathrm{j}}(\mathrm{k}) \\ {\left[\mathrm{Y} \chi_{\mathrm{j}}(\mathrm{k})+\mathrm{Vx}_{\mathrm{c}}(\mathrm{k})\right]^{\mathrm{T}}} & \chi_{\mathrm{j}}(\mathrm{k})^{\mathrm{T}} & \mathrm{I}\end{array}\right)$
$>0, \mathrm{j}=1,2, \ldots 1$,

$\left(\begin{array}{cccccc}\mathrm{Y} & \mathrm{I} & \mathrm{YA}+\mathrm{FC} & \mathrm{Z} & 0 & 0 \\ \mathrm{I} & \mathrm{X} & \mathrm{A} & \mathrm{AX}+\mathrm{BL} & 0 & 0 \\ (\mathrm{YA}+\mathrm{FQ})^{\mathrm{T}} & \mathrm{A}^{\mathrm{T}} & \mathrm{Y} & \mathrm{I} & 0 & \mathrm{Q}^{12} \\ \mathrm{Z}^{\mathrm{T}} & (\mathrm{AX}+\mathrm{BL})^{\mathrm{T}} & \mathrm{I} & \mathrm{X} & \mathrm{L}^{\mathrm{T}} \mathrm{R}^{1 / 2} & \mathrm{XQ}^{1 / 2} \\ 0 & 0 & 0 & \mathrm{R}^{1 / 2} \mathrm{~L} & \mathrm{X} & 0 \\ 0 & 0 & \mathrm{Q}^{12} & \mathrm{Q}^{1 / 2} & 0 & \mathrm{X}\end{array}\right)>0$

$\left(\begin{array}{ccc}\mathrm{Y} & \mathrm{I} & 0 \\ \mathrm{I} & \mathrm{X} & \mathrm{L}^{\mathrm{T}} \\ 0 & \mathrm{~L} & \mathrm{U}_{\max }^{2} \mathrm{I}\end{array}\right)>0$

$\left(\begin{array}{ccc}\mathrm{Y} & \mathrm{I} & \mathrm{A}^{\mathrm{T}} \mathrm{C}^{\mathrm{T}} \\ \mathrm{I} & \mathrm{X} & \mathrm{XA}^{\mathrm{T}} \mathrm{C}^{\mathrm{T}}+\mathrm{L}^{\mathrm{T}} \mathrm{B}^{\mathrm{T}} \mathrm{C}^{\mathrm{T}} \\ \mathrm{CA} & \mathrm{CAX}+\mathrm{CBL} & \mathrm{y}_{\max }^{2} \mathrm{I}\end{array}\right)>0$

Matrices $\mathrm{X}, \mathrm{Y}, \mathrm{L}, \mathrm{M}$ and $\mathrm{Z}$ solutions of the optimization problem (11) are calculated at each instant $\mathrm{k}$ allowing the determination of matrices $\mathrm{A}_{\mathrm{c}}, \mathrm{B}_{\mathrm{c}}$ and $\mathrm{C}_{\mathrm{c}}$ of the dynamic controller.

To determinate a robust dynamic controller (Maherzi et al., 2007), the use of an observer is necessary and can be described as in Fig. 2 and 3. 
Am. J. Applied Sci., 9 (6): 851-857, 2012

The observer can be expressed as follows Eq. 16:

$\left\{\begin{array}{l}\hat{x}(k+1)=A \hat{x}(k)+B u(k)+L_{0}[y(k)-\hat{y}(k)] \\ \hat{y}(k)=C \hat{x}(k)\end{array}\right.$

The observation error is given by Eq. 17:

$\varepsilon=\mathrm{x}-\hat{\mathrm{x}}$

So, the dynamic of the error is given by Eq. 18:

$\varepsilon(\mathrm{k}+1)=\left(\mathrm{A}-\mathrm{L}_{0} \mathrm{C}\right) \varepsilon(\mathrm{k})$

To satisfy the asymptotic stability of (1) using an observer, the following condition must be verified Eq. 19:

$$
\left(\begin{array}{cc}
\mathrm{P} & {\left[\mathrm{A}^{\mathrm{T}} \mathrm{G}^{\mathrm{T}}-\mathrm{C}^{\mathrm{T}} \mathrm{H}^{\mathrm{T}}\right]} \\
{[\mathrm{GA}-\mathrm{HC}]} & {\left[\mathrm{G}+\mathrm{G}^{\mathrm{T}}-\mathrm{P}\right]}
\end{array}\right)>0
$$

The observation gain is given by: $\mathrm{L}_{\mathrm{o}}=\mathrm{G}-{ }^{1} \mathrm{H}$.

Matrices $\mathrm{P}, \mathrm{H}, \mathrm{G}$ solutions of the optimization problem (11), are calculated at each time $\mathrm{k}$ in order to determine the matrices $A_{c}, B_{c}$ and $C_{c}$ defining the dynamic controller.

Designing of the dynamic controller: To design the dynamic controller, we develop the LMI formulation of the constraints based on the invariant ellipsoid technique. We add also the multi-model representation of uncertain system and the observer's stability condition. The set of matrices inequalities allows the calculus of the matrices solution of the optimization problem to deduce the robust dynamic controller (the construction of the controller is updated at each calculation step).

After obtaining the solutions of different systems mentioned above, the construction of the robust dynamic controller can be done by calculating the matrices $\left(\mathrm{A}_{\mathrm{c}}, \mathrm{B}_{\mathrm{c}}\right.$ and $\mathrm{C}_{\mathrm{c}}$ ). Each matrix is given by Eq. 20:

$$
\left\{\begin{array}{c}
\mathrm{A}_{\mathrm{c}}=(1-\mathrm{YX})^{-1} \cdot \mathrm{M} \\
\mathrm{B}_{\mathrm{c}}=(1-\mathrm{YX})^{-1} \cdot \mathrm{F} \\
\mathrm{C}_{\mathrm{c}}=\mathrm{L}
\end{array}\right.
$$

As application, we use the benchmark developed by (Kothare et al., 1994; Zermani et al., 2011) as a numerical example. Eq. 21:

The uncertain system of order 4 is described by

$$
\left\{\begin{array}{l}
\left(\begin{array}{l}
\mathrm{x}_{1}(\mathrm{k}+1) \\
\mathrm{x}_{2}(\mathrm{k}+1) \\
\mathrm{x}_{3}(\mathrm{k}+1) \\
\mathrm{x}_{4}(\mathrm{k}+1)
\end{array}\right)=\left(\begin{array}{cccc}
1 & 0 & 0.1 & 0 \\
0 & 1 & 0 & 0.1 \\
-0.1 \frac{\mathrm{r}}{\mathrm{m}} & 0.1 \frac{\mathrm{r}}{\mathrm{m}} & 1 & 0 \\
0.1 \frac{\mathrm{r}}{\mathrm{m}} & -0.1 \frac{\mathrm{r}}{\mathrm{m}} & 0 & 1
\end{array}\right)\left(\begin{array}{l}
\mathrm{x}_{1}(\mathrm{k}) \\
\mathrm{x}_{2}(\mathrm{k}) \\
\mathrm{x}_{3}(\mathrm{k}) \\
\mathrm{x}_{4}(\mathrm{k})
\end{array}\right)+\left(\begin{array}{c}
0 \\
0 \\
0.1 \\
\mathrm{~m} \\
0
\end{array}\right) \mathrm{u}(\mathrm{k}) \\
\mathrm{y}(\mathrm{k})=\left(\begin{array}{llll}
1 & 0 & 0 & 0 \\
0 & 1 & 0 & 0
\end{array}\right)\left(\begin{array}{l}
\mathrm{x}_{1}(\mathrm{k}) \\
\mathrm{x}_{2}(\mathrm{k}) \\
\mathrm{x}_{3}(\mathrm{k}) \\
\mathrm{x}_{4}(\mathrm{k})
\end{array}\right)
\end{array}\right.
$$

$\mathrm{m}$ is the masse equal to 1 and $\mathrm{r}$ is the spring constant. $r \in[0.1,2.1]$ : subject of uncertainty.

The value of the input constraint is $u_{\max }=1$.

Positions of the two masses are given by $x_{1}$ and $x_{2}$, while $\mathrm{x}_{3}$ and $\mathrm{x}_{4}$ are their speeds which are unmeasured. Let consider the multi-model representation of the uncertainty in $\mathrm{A}$ is given by Eq. 22:

$$
\mathrm{A}=\sum_{\mathrm{j}=1}^{2} \alpha_{\mathrm{j}} \mathrm{A}_{\mathrm{j}}
$$

Where:

$$
\begin{aligned}
\mathrm{A}_{1} & =\left(\begin{array}{cccc}
1 & 0 & 0.1 & 0 \\
0 & 1 & 0 & 0.1 \\
-0.1 \mathrm{r}_{\min } & 0.1 \mathrm{r}_{\min } & 1 & 0 \\
0.1 \mathrm{r}_{\min } & -0.1 \mathrm{r}_{\min } & 0 & 1
\end{array}\right) \\
\mathrm{A}_{2} & =\left(\begin{array}{cccc}
1 & 0 & 0.1 & 0 \\
0 & 1 & 0 & 0.1 \\
-0.1 \mathrm{r}_{\max } & 0.1 \mathrm{r}_{\max } & 1 & 0 \\
0.1 \mathrm{r}_{\max } & -0.1 \mathrm{r}_{\max } & 0 & 1
\end{array}\right)
\end{aligned}
$$

And $\alpha_{j}$ the activation function satisfying Eq. 23:

$$
\sum_{\mathrm{j}=1}^{2} \alpha_{\mathrm{j}}=1
$$

With:

$$
\left\{\begin{array}{l}
\alpha_{1}=1-\tanh \left(\mathrm{x}_{1}(\mathrm{k})\right) / 2 \\
\alpha_{1}=1-\alpha_{2}
\end{array}\right.
$$

Initial conditions of the system and the dynamic controller are respectively

- $\quad x(0)=\left[\begin{array}{llll}1 & 1 & 0 & 0\end{array}\right]^{\mathrm{T}}$

- $\quad x_{c}(0)=\left[\begin{array}{llll}0 & 0 & 0 & 0\end{array}\right]^{\mathrm{T}}$ 


\section{RESULTS}

The resolution of different inequalities constituting the optimization problem via the LMI formulation with Matlab@ software is given as follows.

The multi-model representation gives as the opportunity to find an interval $\left[r_{\min }, r_{\max }\right]$ generating the maximum variation of the uncertainty and for which matrix inequalities for the optimization problem still feasible.

\section{Without observer:}

- $\quad$ For $r m i n=0.9$ and $\operatorname{rmax}=1.1$ :

The execution of the algorithm on Matlab (C) allows for minimal $\gamma$ and the responses on closed-loop of the uncertain system. The behavior of the responses system $\left(\mathrm{y}_{1}\right.$ and $\left.\mathrm{y}_{2}\right)$ is given by Fig. 4 .

The minimal value of $\gamma$ is 90.8722 .

Figure 4 proves that the robust dynamic controller stabilizes the uncertain system. Hence the efficiency of the study proposed in this study.

- $\quad$ For $r_{\min }=0.1$ and $r_{\max }=2.1$ :

The execution gives:

The minimal value of $\gamma$ is 90.8722 .

We observe a transient behavior of the responses system $\left(\mathrm{y}_{1}\right.$ and $\left.\mathrm{y}_{2}\right)$ at the beginning. In permanent regime, the robust dynamic controller stabilizes the uncertain system: confirmation of the effectiveness of the proposed study.

With observer: The use of the observer gives the following results:

- $\quad$ For $\mathrm{r}_{\min }=0.9$ and $\mathrm{r}_{\max }=1.1$ :

The minimal value of $\gamma$ is 90.8722 .

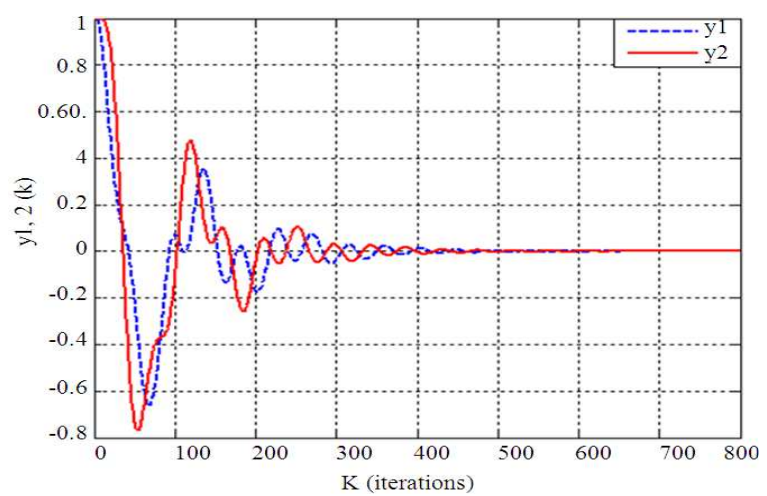

Fig. 4: The time responses of the system outputs for $r \in$ $[0.9,1.1]$

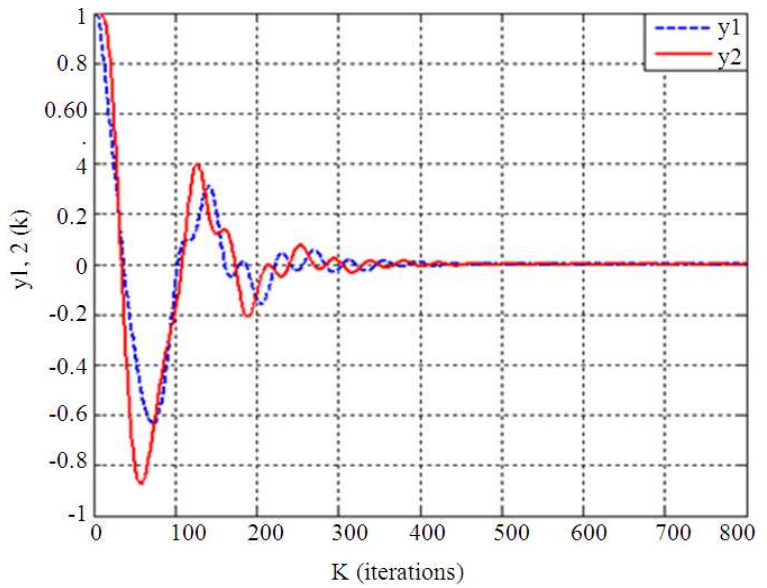

Fig. 5: The time responses of the system outputs for $r \in$ $[0.1,2.2]$

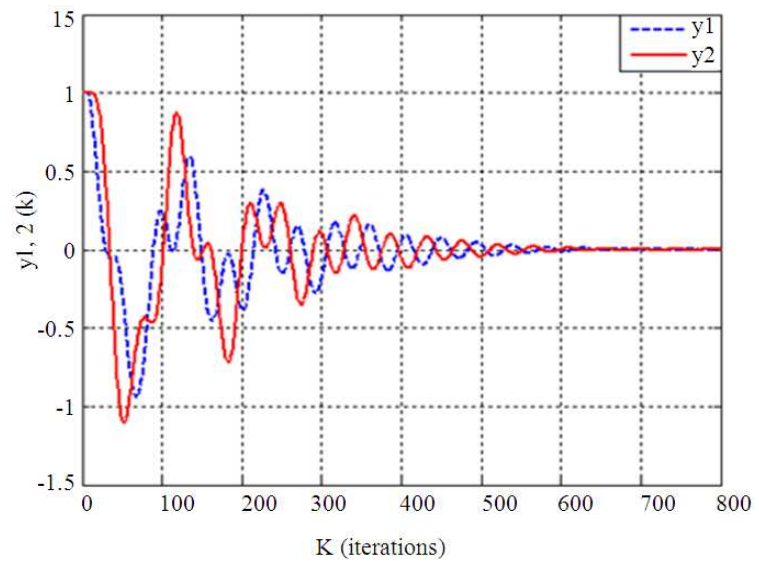

Fig. 6: The time responses of the system outputs with observer for $r \in[0.9,1.1]$

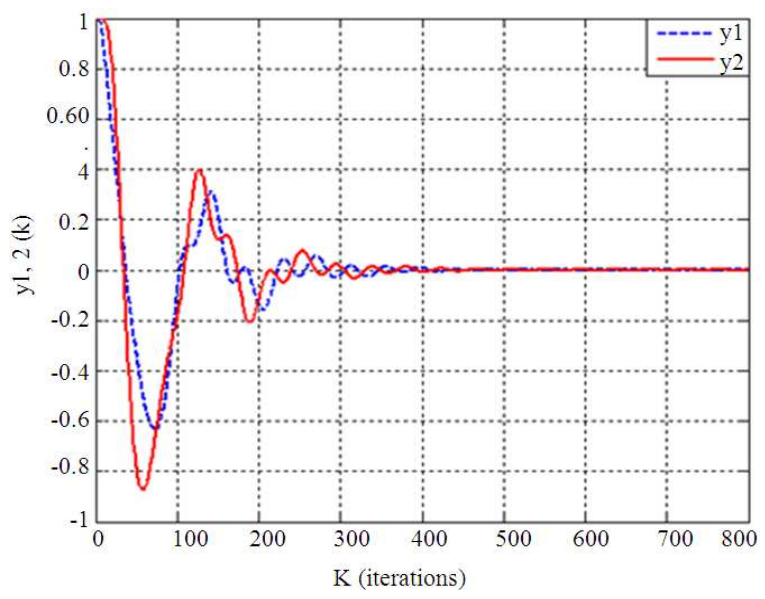

Fig. 7: The time responses of the system outputs with observer $r \in[0.1,2.2]$ 
Am. J. Applied Sci., 9 (6): 851-857, 2012

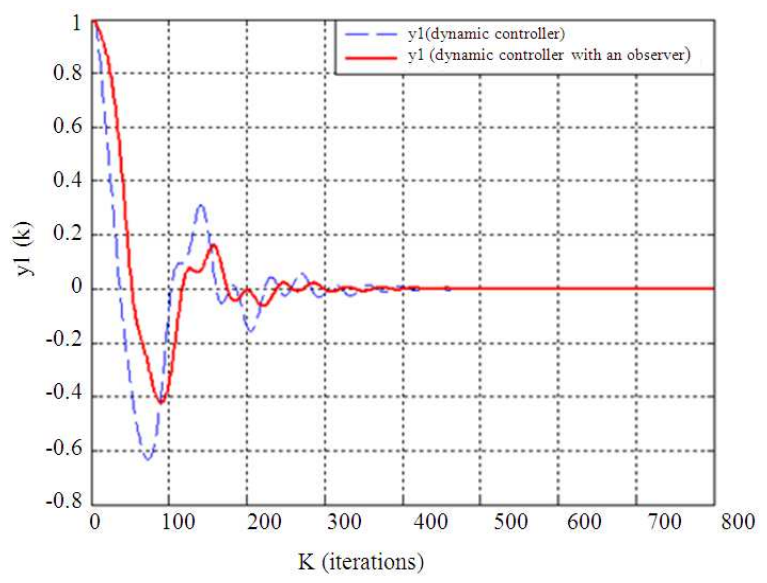

Fig. 8: The system responses $y_{1}$

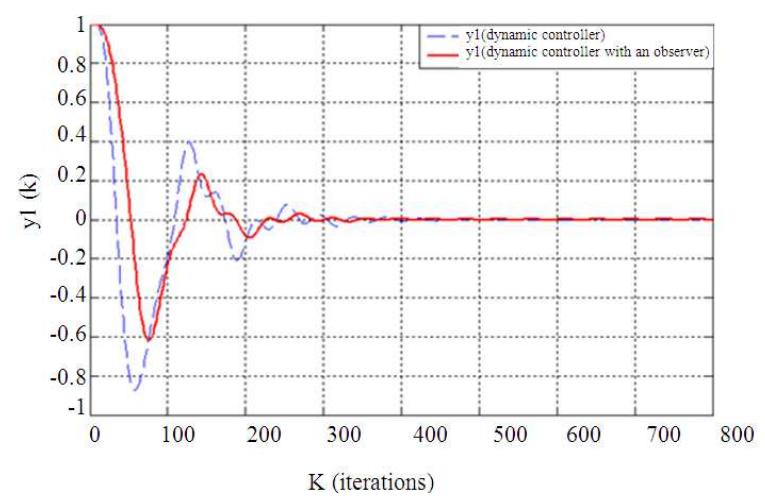

Fig. 9: The system response $y_{2}$

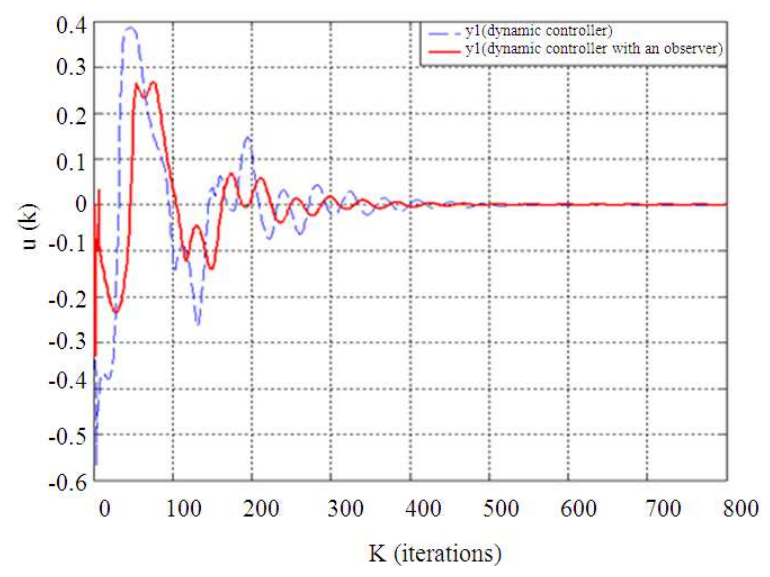

Fig. 10: The control low behavior

The dynamic controller guarantees the stability of the system and despite the oscillations:

- For $r \min =0.1$ and $r_{\max }=2.1$ :
The minimal value of $\gamma$ is 90.8722 .

We note that the controller stabilizes the system in case, faster than previously case.

\section{DISCUSSION}

A comparison study is developed in this study.

Different results prove the effectiveness of the study developed in this study. We note that the response of the controlled system with observer is less oscillatory than the system controlled without observer. The stabilization of the system is verified.

We also note that for large ranges of uncertainty, the behaviour of the response of the outputs of the controlled system with observer is the best as proved in following Fig. 5-7.

Figure 8-10 gives respectively the system responses $y_{1}, y_{2}$ and the optimal control low $u$ in the two cases (with and without observer).

The dynamic controller with the observer is more robust than without observer in term of stability of the system.

\section{CONCLUSION}

In this study, we present a design of dynamic controller by resolving an optimization problem to control an uncertain system described by multi-model approach. The developed robust dynamic controller is based on predictive control low. This study is validated by an illustrative example and the implementation of the LMI formulation of the optimization problem in Matlab $\odot$ or Scilab@. The results proof the efficiency and utility of the proposed study and we note that for large ranges of uncertainty, the behavior of the response of the outputs of the controlled system with observer is better.

\section{REFERENCES}

Ababneh, M., I. Etier, M. Smadi and J. Ghaeb, 2011. Synchronization of chaos systems using fuzzy logic. J. Comput. Sci., 7: 197-205. DOI: 10.3844/jcssp.2011.197.205

Akhenak, A., M. Chadli, D. Maquin and J. Ragot, 2004. State estimation of uncertain multiple model with unknown inputs. Proceeding of the 43rd IEEE Conference on Decision and Control, Dec. 14-17, IEEE Xplore Press, USA., pp: 3563-3568. DOI: 10.1109/CDC.2004.1429265

Boyd, S., L.E. Ghaoui, E. Feron and V. Balakrishnan. 1994. Linear Matrix Inequalities in System and Control Theory. 1st Edn., SIAM, Philadelphia, ISBN: 0898714850, pp: 203. 
Chadli, M., 2002. Stability and control of systems described by multi-models. Thesis, Doctoral school IAEM, Lorraine, France.

Chadli, M., A. Akhenak, J. Ragot and D. Maquin, 2009. State and unknown input estimation for discrete time multiple model. J. Franklin Inst. 346: 593610. DOI: 10.1016/j.jfranklin.2009.02.011

ElFelly, N., J. Dieulot, P. Borne and M. Benrejeb, 2010. A Multimodel approach of complex systems identification and control using neural and fuzzy clustering algorithms. Proceedings of the 9th International Conference on Machine Learning and Applications (ICMLA), Dec. 12-14, IEEE Xplore Press, Washington, DC., pp: 93-98. DOI: 10.1109/ICMLA.2010.21

Kanthalakshmi, S. and V. Manikandan, 2011. Fault tolerant control using proportional-integralderivative controller tuned by genetic algorithm. J. Comput. Sci., 7: 1187-1193. DOI: 10.3844/jcssp.2011.1187.1193

Kothare, M., V. Balakrishnan and M. Morari, 1994. Robust constrained model predictive control using linear matrix inequalities. Automatica, 32: 440444. DOI: 10.1109/ACC.1994.751775
Maherzi, E., J. Bernussou and R. Mhiri, 2007. Stability and stabilization for uncertain switched systems, a polyquadratic Lyapunov approach. Int. J. Sci. Tech. Automatic Control, 1: 61-73.

Richalet, J., G. Lavielle and J. Mallet, 2005. Predictive control: Implementation and industrial applications. Editions Eyrolles.

Santhakumar, M. and T. Asokan, 2010. A self-tuning proportional-integral-derivative controller for an autonomous underwater vehicle, based on taguchi method. J. Comput. Sci., 6: 862-871. DOI: 10.3844/jcssp.2010.862.871

Torre, M. and E.G. Migliore, 2011. Design and implementation of a predictive control strategy based on an industrial controller. IEEE Latin Am. Trans., 9: 638-643. DOI: 10.1109/TLA.2011.6030970

Zermani, M.A., E. Feki and A. Mami, 2011. Application of adaptive predictive control to a newborn incubator. Am. J. Eng. Applied Sci., 4: 235-243. DOI: 10.3844/ajeassp.2011.235.243 